\title{
Complete surgical excision of a huge left ventricular fibroma
}

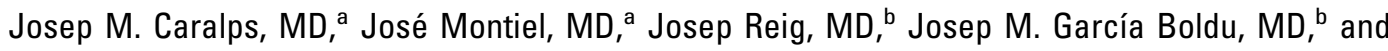 \\ Francesc Carreras, MD, ${ }^{a}$ Barcelona and Manresa, Spain
}

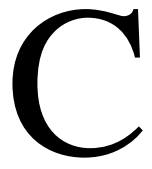

ardiac fibromas are infrequent tumors, and although they are histologically benign, their location and size may be responsible for hemodynamic compromise or ventricular arrhythmias that can cause sudden death. Therefore, once diagnosis is made, surgical excision is the best option. ${ }^{1}$

\section{Clinical Summary}

A 25-year-old woman was seen by her doctor because of nonspecific chest pains. The patient had no risk factors for ischemic heart disease, but in the electrocardiogram there were nonspecific repolarization changes; a myocardial single-photon emission computed tomography scan showed a large anterolateral perfusion defect with deformity of the surrounding tissue, thus suggesting intramural growth. Magnetic resonance imaging disclosed the presence of an intramural ventricular mass $(6 \times 9 \times 5 \mathrm{~cm})$ occupying the entire anterolateral left ventricular wall (Figure 1). The tumor was pushing the septum rightward and restricted left ventricular filling. In the coronal view, the mass was seen surrounded by normal myocardium. With the diagnosis of fibroma, the patient was sent to operation.

Through median sternotomy, the pericardium was opened, and a bulging mass appeared that extended from the apex to the base of the left ventricle and from the anterior descending artery to the obtuse margin of the heart. The surface was irregular and grayish. Cardiopulmonary bypass was established, and the aorta was crossclamped under cardioplegic arrest. The epicardium was then incised $3 \mathrm{~cm}$ lateral to the anterior descending artery; a cleavage plane could be developed between the tumor and normal muscle. With patience and sharp careful dissection, this plane was developed all around the mass without entering the ventricular cavity, thus permitting total enucleation of the tumor; the epicardium was then closed with a continuous layer of 3-0 monofilament suture. No attempt was made to obliterate the cavity left in the myocardium by the tumor. The tumor measured $9 \times 7 \times 5 \mathrm{~cm}$ and weighed $200 \mathrm{~g}$ (Figure 2). The patient

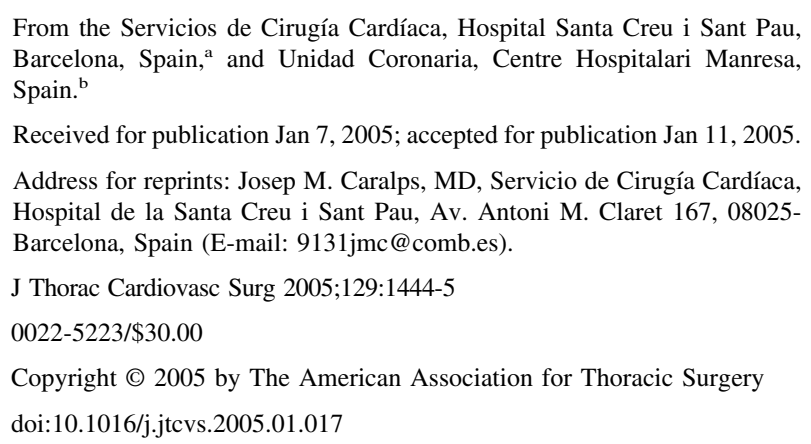

came off bypass without problems; transesophageal echocardiogram showed the presence of a small residual cavity in the left ventricular wall; it had no hemodynamic significance. Pathology confirmed the clinical diagnosis of fibroma; the patient was sent home 1 week after surgery. In a magnetic resonance imaging scan performed 6 months later, the cavity was smaller. Three years later, it had completely disappeared. The patient is asymptomatic and leading a normal life.

\section{Discussion}

Cardiac fibromas represent only $3 \%$ of all cardiac tumors; they are more frequently encountered in children and adolescents, are usually single and intramural, and are mainly located in the septum and in the free wall of the left ventricle. Clinical findings are dependent on the size and location of the tumor, but the patients usually complain of chest pains, palpitations, and nonspecific thoracic discomfort. Congestive heart failure and ventricular arrhythmias, although infrequent, may be the first clinical manifestation in large tumors. ${ }^{1}$

Diagnosis of a left ventricular mass is usually made by echocardiography, but magnetic resonance, with a wider vision field and better capacity of tissular characterization, is the ideal tool to confirm diagnosis, define the extent of tumor involvement, and plan the surgical approach. ${ }^{2}$

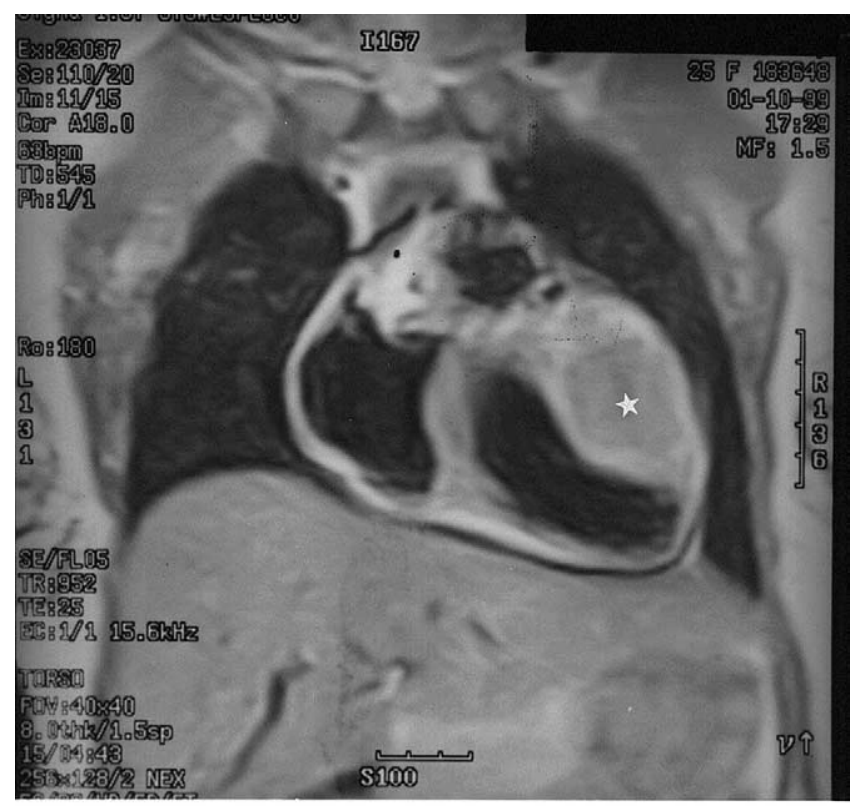

Figure 1. Coronal T1-weighted spin-echo image showing a large mass with sharp borders and no pericardial infiltration located in the anterior left ventricular wall. 


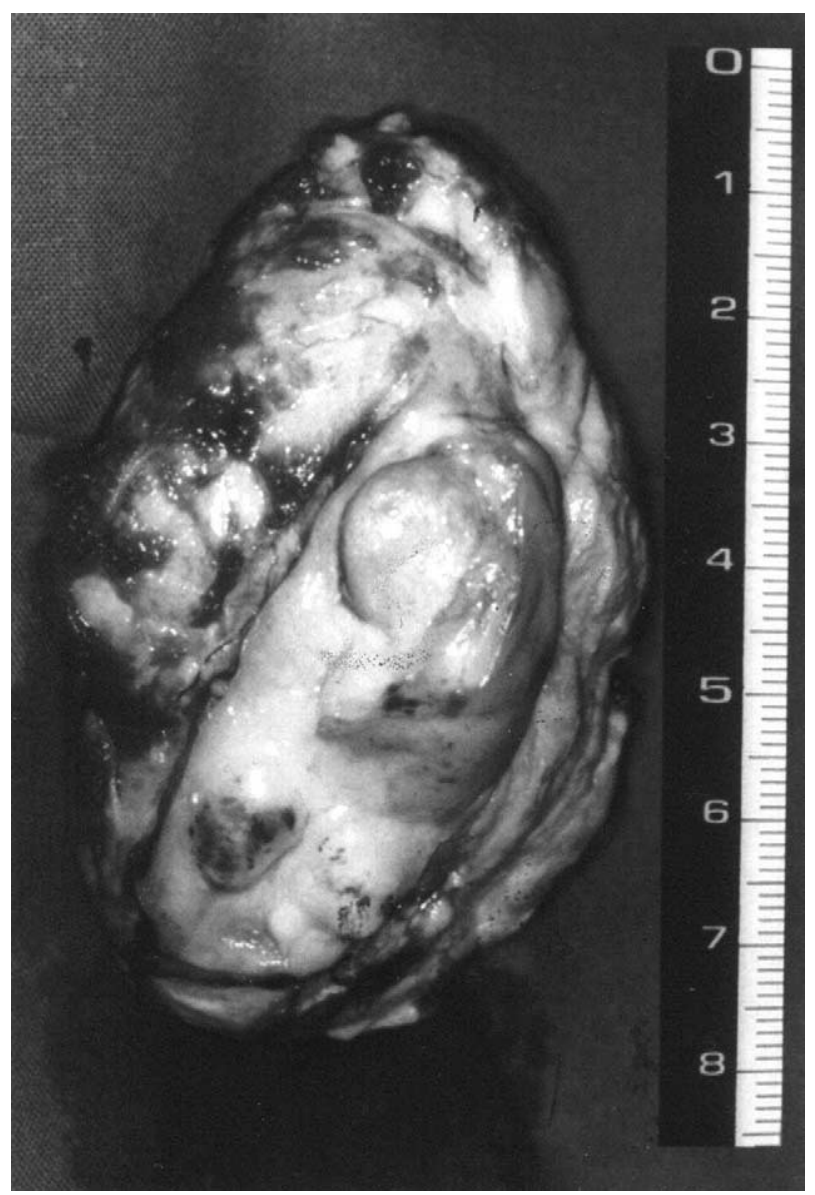

Figure 2. The resected tumor.
Even though these tumors show a slow rate of growth, sudden deaths from malignant ventricular arrhythmias for displacement or compression of the conduction system have been described in approximately $10 \%$ of patients with this pathology. Once they are diagnosed, we think that these tumors should be excised irrespective of symptoms. At operation, complete resection should be attempted to avoid recurrence and to improve prognosis. Although in the past good long-term results were reported with partial excision, ${ }^{3}$ with the techniques available today, the size or location of the tumor do not preclude complete and safe excision, so transplantation, suggested by some as a preferable operation, should not be the first option. ${ }^{4}$ Even in the presence of extensive endocardial and paravalvular involvement, complete resections have been reported that used complex surgical techniques. ${ }^{5}$ In our case, careful dissection enabled us to dissect the tumor from healthy surrounding muscle; the cavity in the wall of the left ventricle needed no specific therapy.

\section{References}

1. Parneley FL, Salley RK, Williams JP, Head GB. The clinical spectrum of cardiac fibroma with diagnostic and surgical considerations: noninvasive imaging enhances management. Ann Thorac Surg. 1988;45:455-65.

2. Burke AP, Rosado-de-Christenson M, Templeton PA, Virmani R. Cardiac fibroma: clinicopathological correlates and surgical treatment. J Cardiovasc Surg. 1994;108:862-70.

3. Ceithaml EL, Midgley FM, Perry LM, Dullum M. Intramural ventricular fibroma in infancy: survival after partial excision in 2 patients. Ann Thorac Surg. 1990;50:471-2.

4. Aufiero TX, Pae WE, Clemson BS, Pawlush DG, Davis D. Heart transplantation for tumor. Ann Thorac Surg. 1993;56:1174-6.

5. Grinda JM, Chachques JC, Jovan J, La Trenouille C, Deloche A, Carpentier AF. Left ventricular reconstruction after resection of a large fibroma. Ann Thorac Surg. 2001;71:1354-6. 